\title{
Determination of material properties for short fibre reinforced C/C-SiC
}

\author{
J.-M. Hausherr ${ }^{1, \mathrm{a}}$, M. Eitel $^{1}$ and W. Krenkel ${ }^{2}$ \\ ${ }^{1}$ Fraunhofer-Institut für Silicatforschung ISC, HTL Bayreuth, Germany \\ ${ }^{2}$ Department Ceramic Materials Engineering, University of Bayreuth, Bayreuth, Germany
}

\begin{abstract}
Determining the mechanical properties of short fibre reinforced CMC using standard sized coupons has always been a challenge due to a high statistical scattering of the measured values. Although the random orientation of short fibres results in a quasi-isotropic material behavior of 2D-structures with a sufficiently large volume, the small volume typical for test coupons usually results in a non-isotropic fibre orientation in the tested volume. This paper describes a method for manufacturing unidirectional oriented short fibre reinforced $\mathrm{CMC}$ materials and presents material properties of UD-C/C-SiC. After verifying the fibre orientation of the $\mathrm{CMC}$ using micro-computed tomography, coupons were extracted to determine the orthotropic material properties. These orthotropic material properties were then used to predict the properties of $\mathrm{C} / \mathrm{C}$-SiC with randomly distributed short fibres. To validate the method, micro-computed tomography is used to quantitatively determine the fibre orientation within coupons extracted from randomly distributed short fibre $\mathrm{C} / \mathrm{C}-\mathrm{SiC}$. After mechanical three-point-bending tests, the measured stiffness and bending strength is compared with the predicted properties. Finally, the data are used to devise a method suited for reducing the inherent large spread of material properties associated with the measurement of CMC materials with randomly distributed short fibres.
\end{abstract}

\section{Introduction}

Material testing of randomly distributed short fibre reinforced composites has always been challenging due to the large spread of material properties. Coupons with standardized geometric sizes are typically extracted from large plates manufactured using sheet moulding techniques. Due to the small coupon size, the mechanical properties are influenced from the locally inhomogeneous fibre distribution. This necessiates a large number of specimens to ensure that the material properties are statistically determined, resulting in high costs and a high scattering of the data obtained.

A solution commonly used in polymer reinforced materials involves the manufacturing of coupons with all short fibres oriented in one direction using techniques such as injection moulding [1]. Due to the flow processes involved, the short fibres within the polymer orient themselves in one direction, resulting in an orthotropic material suited for determining orthotropic material properties. The obtained orthotropic data is used as a basis to calculate the material properties of the composite with random fibre distribution [2].

\footnotetext{
${ }^{\text {a }}$ Corresponding author: jan.hausherr@isc.fraunhofer.de
}

This is an Open Access article distributed under the terms of the Creative Commons Attribution License 4.0, which permits unrestricted use, distribution, and reproduction in any medium, provided the original work is properly cited. 


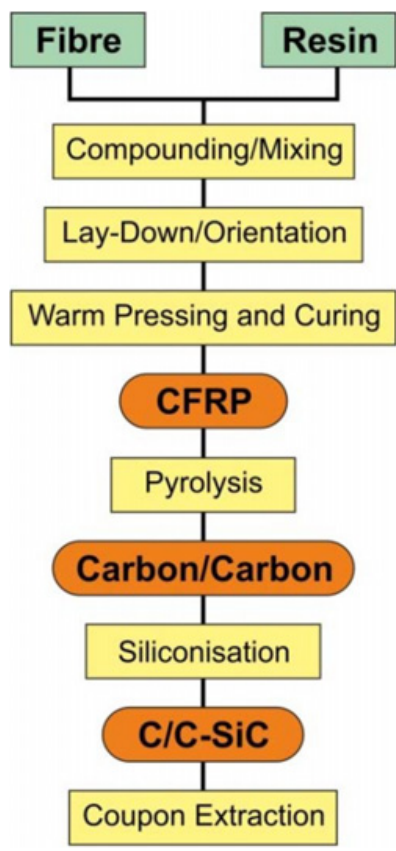

Figure 1. The Liquid Silicon Infiltration Process (LSI).

The microstructure of ceramic matrix composites such as short fibre reinforced silicon carbide (SF$\mathrm{C} / \mathrm{C}-\mathrm{SiC}$ ) consists of carbon fibre bundles embedded in a silicon carbide matrix. During the typical manufacturing process using the Liquid Silicon Infiltration method (LSI), it is essential that the compact bundles of short carbon-fibres remain intact during the infiltration process with liquid silicon. This is achieved by manufacturing a green-body consisting of short fibre bundles and a matrix of phenolic resin. To ensure the integrity of the fibre bundles, the process of warm-pressing is typically used [3, 4].

Typical manufacturing processes used for polymer composites, such as pultrusion, injection moulding or other methods that automatically align the short fibres in a certain direction cannot ensure the integrity of the fibre bundles, prohibiting their use in the manufacture of SF-C/C-SiC $[1,5]$.

The high scattering of material properties measured from randomly distributed short fibre reinforced material has been described in several papers [5]. Henrichs et al presented tensile testing of short fibre reinforced $\mathrm{C} / \mathrm{C}-\mathrm{SiC}$, measuring a tensile strength of $12 \mathrm{MPa}$ with a standard deviation of $4 \mathrm{MPa}$. [6]. Flexural testing of similar material from Weiss et al show a flexural strength of $50 \mathrm{MPa}$ with a standard deviation of $15 \mathrm{MPa}$ [7].

Heim et al. determined a similar high scattering of data occurring during flexural testing of short carbon fibre reinforced plastics (flexural strength of $80 \mathrm{MPa}$, standard deviation of $30 \mathrm{MPa}$ ) and carbon reinforced carbon (flexural strength of $20 \mathrm{MPa}$ and standard deviation of $5 \mathrm{MPa}$ ) [8].

\section{Coupon manufacturing}

For coupon testing, a total of 12 plates $(205 \mathrm{~mm} \times 205 \mathrm{~mm}$, thickness $3 \mathrm{~mm})$ made of SF-C/C-SiC plates were manufactured. In 4 plates the short fibres were randomly distributed, the remaining 8 plates consisted of unidirectionally oriented fibre bundles. All plates were processed under identical conditions and manufactured from one common batch of phenolic resin and short fibre carbon compound.

Manufacturing was performed using the three step LSI process as described in Fig. 1 [9]. 


\subsection{Green-body manufacturing}

Green-body manufacturing was performed using $3 \mathrm{k}$ carbon short fibre bundles of the type HTA (TORAY Industries) with a bundle length of $6 \mathrm{~mm}$. The fibre bundles were mixed with finely powdered phenolic resin (1:1 ratio by weight) to ensure a final fibre volume content of $65 \%( \pm 2 \%)$.

After mixing, the randomly oriented fibre-resin mix was weighed. To ensure a constant thickness of $3 \mathrm{~mm}$ for each plate, the square warm-pressing mould with dimensions $210 \mathrm{~mm} \times 210 \mathrm{~mm}$ was filled with $360 \mathrm{~g}$ of compound.

\subsection{Manufacturing plates with aligned fibres}

To obtain a defined orientation of the fibre bundles, the process described for green-body manufacturing was applied. However, before filling the fibre-resin mix into the mould, a grating of thin steel spacers with $3 \mathrm{~mm}$ distance was vertically placed into the mould (Fig. 2a).

The compound of short fibre bundle and phenolic resin powder was then carefully poured into the mould (Fig. 2b). Due to the fibre bundle length of $6 \mathrm{~mm}$, the grating aligned all fibres parallel to the grating (Fig. 2c).

After the filling process is completed, the spacers are carefully removed from the mould without interfering with the aligned fibre bundles and the compound is warm pressed. Due to the uniaxial loading of the mould during warm-pressing, the orientation of the fibre bundles within the mould was not disturbed. After warm-pressing, the green-body plates contained unidirectionally aligned short carbon fibres in a phenolic resin matrix (Fig. 2d).

\subsection{Pyrolysis}

The pyrolysis occurred at temperatures up to $1600^{\circ} \mathrm{C}$ under nitrogen gas atmosphere, converting the plates into a carbon-carbon intermediate state. The plates were stacked between graphite blocks and weighed down to prevent possible warping.

After pyrolysis, the open porosity of the plates was determined using buoancy method according to DIN EN 1389 [10]. All plates had a similar open porosity of $23 \%( \pm 3 \%)$.

\subsection{Melt infiltration}

The melt infiltration of silicon was performed at $1600^{\circ} \mathrm{C}$. The plates were placed vertically in a boron nitride coated crucible and supported by boron nitride coated graphite backing. Granulated silicon with a purity of $99.8 \%$ was provided. To ensure a complete conversion into $\mathrm{C} / \mathrm{C}-\mathrm{SiC}$, an excess of silicon was offered (150\% of the necessary amount). The open porosity of the final C/C-SiC-ceramic plates was determined using buoancy method according to DIN EN 1389. All plates had a similar open porosity of $4.5 \%( \pm 0.5 \%)$.

\subsection{Coupon extraction}

Coupons were extracted from the $\mathrm{C} / \mathrm{C}$-SiC plates using a water cooled diamond cutting machine of the type ATM Brilliant 270.

The coupon size was $70 \mathrm{~mm} \times 10 \mathrm{~mm}$ and extracted according to the standards DIN EN 658-3 [11] for fibre reinforced ceramic materials. For determining the influence of fibre orientation, coupons were prepared from unidirectional material at an angle of $0^{\circ}, 15^{\circ}, 30^{\circ}, 45^{\circ}, 60^{\circ}, 75^{\circ}$ and $90^{\circ}$ (Fig. 3). For each angle a minimum of 20 coupons were prepared (Table 1). 


\section{MATEC Web of Conferences}

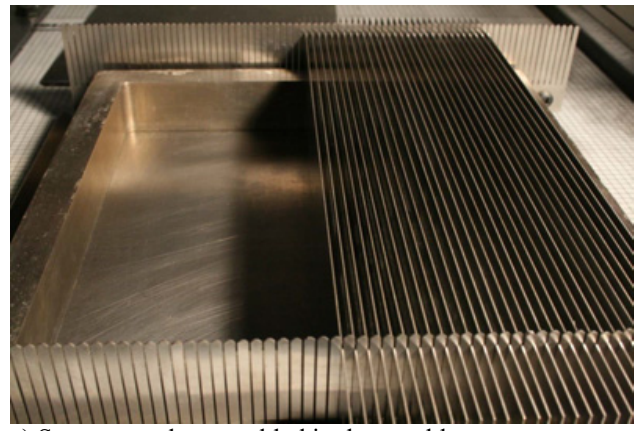

a) Spacers partly assembled in the mould

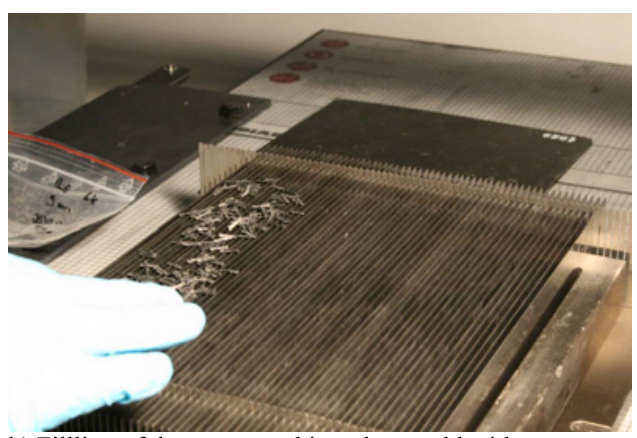

b) Fillling of the compound into the mould with spacers.

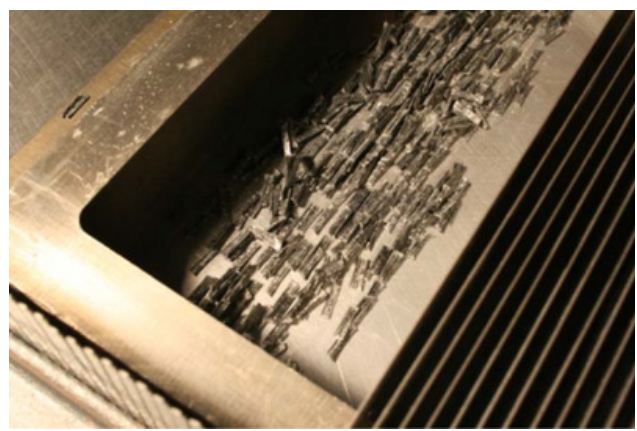

c) Orientation of the fibre bundles due to the spacers.

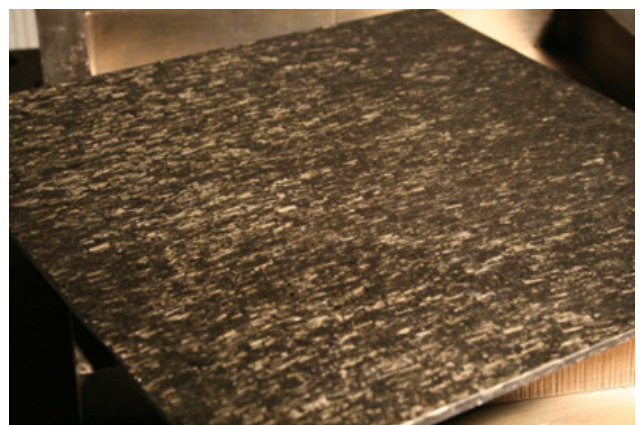

d) Green-body plate consisting of unidirectionally oriented short carbon-fibres in a phenolic resin.

Figure 2. Manufacturing steps of unidirectionally aligned SF-C/C-SiC. 


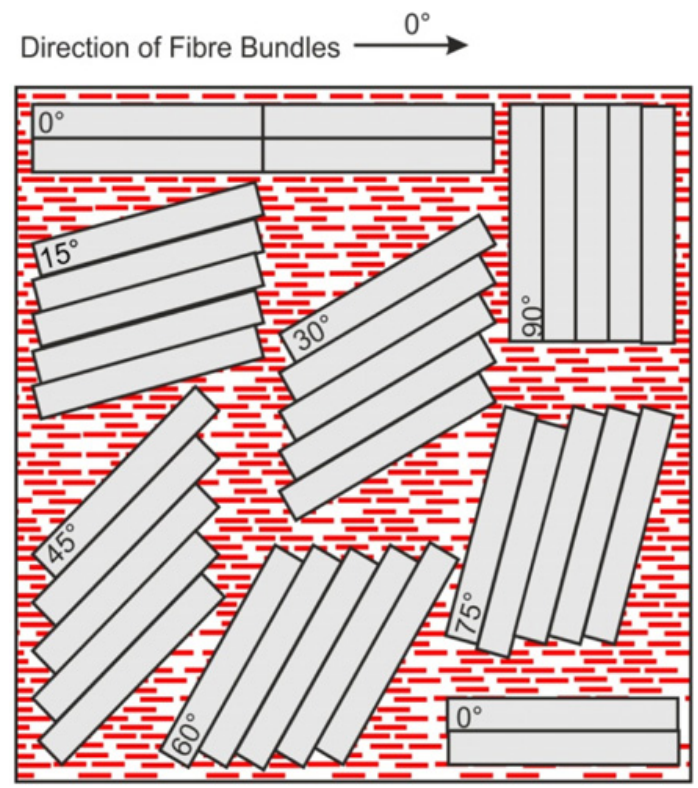

Figure 3. Coupon data: Extraction plan (oriented fibre bundles are red).

Table 1. Number of coupons extracted for each direction.

\begin{tabular}{|l|l|l|l|l|l|l|l|}
\hline Orientation & $0^{\circ}$ & $15^{\circ}$ & $30^{\circ}$ & $45^{\circ}$ & $60^{\circ}$ & $75^{\circ}$ & $90^{\circ}$ \\
\hline Number of coupons & 40 & 20 & 20 & 40 & 20 & 20 & 40 \\
\hline
\end{tabular}

Additionally, 20 coupons with dimension $70 \mathrm{~mm} \times 20 \mathrm{~mm}$ and another 20 coupons with dimension $70 \mathrm{~mm} \times 30 \mathrm{~mm}$ were extracted from randomly distributed material.

\section{Experimental procedures}

\subsection{Determining fibre distribution using computed tomography}

To validate the orientation of the short fibres, the method of micro-computed tomography ( $\mu \mathrm{CT}$ ) was used to quantitatively determine the in-plane fibre orientation. CT analysis was performed both on the plates before coupon extraction and on each coupon to ensure the appropriate orientation or random distribution of the fibres is achieved. $\mu \mathrm{CT}$ volumetric analysis was performed with a testing resolution of 25 microns.

Fibre Orientation. Fibre orientation is determined by analyzing the volumetric data using a structure tensor algorithm (Fig. 4) as described by Krause et al. [12, 13].

The algorithm provides a histogram plot of the percentage of fibres oriented in a certain direction within the coupon volume. Figure 5 shows an example of the fibre distribution determined in a coupon with approximately $65 \%$ of all fibres aligned in $0^{\circ}$ direction with a maximal $\pm 10^{\circ}$ spread.

Quality Control of Coupons. To ensure that the mechanical properties were an effect of fibre orientation, each coupon was tested for proper alignment. Any coupons having less than 55\% of their total fibre bundles aligned within $\pm 10^{\circ}$ to each other were rejected from testing.

All coupons were additionally tested for defects that would influence the results of mechanical testing, such as cracks, pores or inhomogeneous areas within the material. Cracks of a length greater 


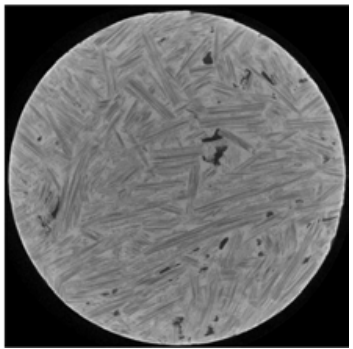

a) Original slice of specimen.

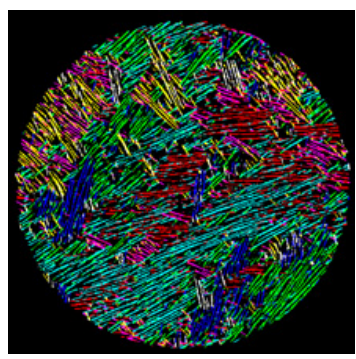

c) Determination of the fibre orientation using the structure tensor approach (orientation is color coded).

Figure 4. Structure tensor approach to determine fibre orientation.

than 300 microns and pores with a diameter larger than 100 microns result in a rejection of coupons for further testing.

\subsection{Mechanical testing}

To determine the effect of fibre orientation, three point bending testing was performed on coupons extracted both from unidirectional and randomly distributed material. The effects of the fibre alignment are determined by coupons extracted from UD material at different angles according to Table 1.

\section{Definitions of Orientation}

Due to the warm pressing process, all fibre bundles have a forced orientation in $\mathrm{u}-\mathrm{v}$-plane of the plate (Fig. 6a). The u-v-plane of the plate corresponds with the $x$-y-plane of the coupons (Fig. 6b).

For determining effects of orientation, fibre alignment is defined with regard to the coupon length. Coupons with oriented fibres aligned parallel to the coupon length are defined to have a $0^{\circ}$ orientation. Any angular offset of the fibre bundles is specified as seen in Fig. 6 b.

\section{Testing Conditions}

The standard DIN EN 658 specifically describes the testing of ceramic composite materials made of fabrics or endless fibres embedded in a ceramic matrix. Due to a lack of specific standards regarding the testing of short fibre reinforced CMC, it was decided that the testing conditions described in DIN EN 658 are sufficient for the tests.

Coupon size was $70 \mathrm{~mm} \times 10 \mathrm{~mm} \times 3 \mathrm{~mm}$, the supporting pins were placed $60 \mathrm{~mm}$ apart. The testing frame was a Hegewald \& Peschke Inspect Table $100 \mathrm{kN}$, using a $2 \mathrm{kN}$ loading cell. A load speed of $1 \mathrm{~mm} / \mathrm{min}$ was chosen after assuring that failure occurred within 60 seconds after applying initial load. Deformation of the coupons was measured using an inductive sensor placed precisely under the middle of the coupon. Load and displacement was recorded 50 times per second until ultimate failure occurred. 


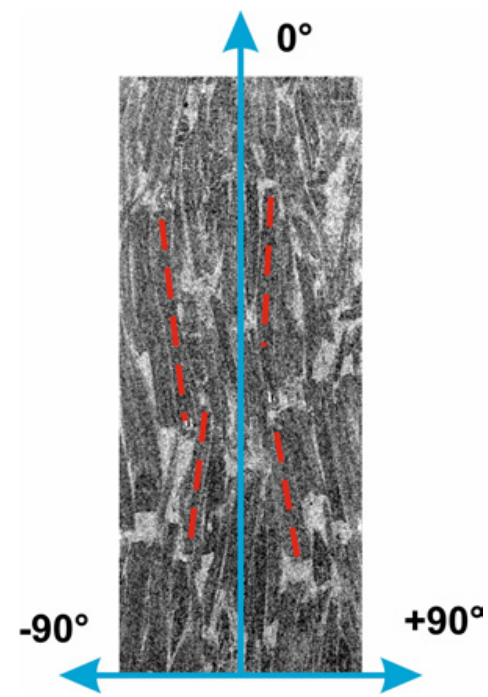

a) Cross section of a coupon with carbon fibre bundles visible as dark rectangles.

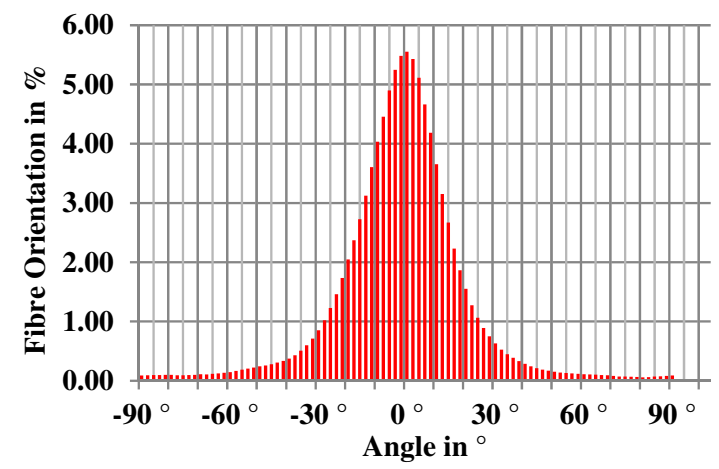

b) Histogram of the fibre bundle distribution in an aligned SF$\mathrm{C} / \mathrm{C}-\mathrm{SiC}$ material.

Figure 5. Fibre orientation in coupons.

For the determination of bending stiffness, a region of linear elasticity was determined by subjecting the coupons to a series of repetitive loading-unloading cycles with increasing load. The stress-straincurves of both unidirectional and randomly oriented material indicated linear elastic behavior occurring at bending stresses less than $25 \%$ of the ultimate load.

Bending stiffness was therefore determined from the stress-strain-curves in a region between $5 \%$ und $20 \%$ of the ultimate load.

\section{Results}

\subsection{Computed tomography}

Analysis of Unidirectional Material

The computed tomography data show a good alignment of the fibre bundles. However, a perfect alignment of the fibre bundles is not possible due to the occurrence of a minor overlap at their ends, 


\section{MATEC Web of Conferences}

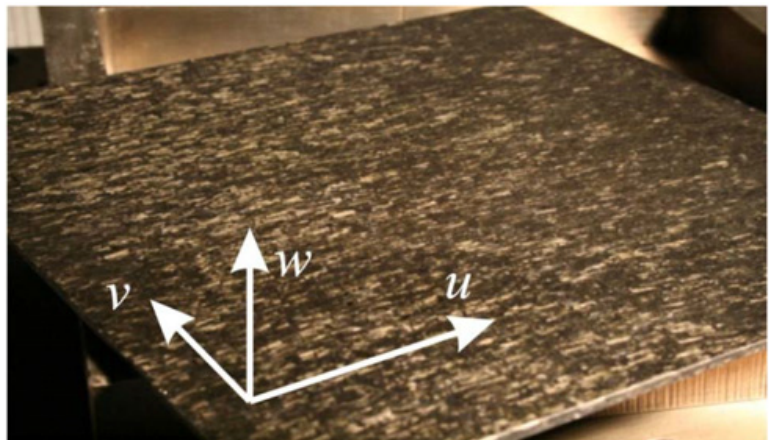

a) Definition of fibre alignment in the plates

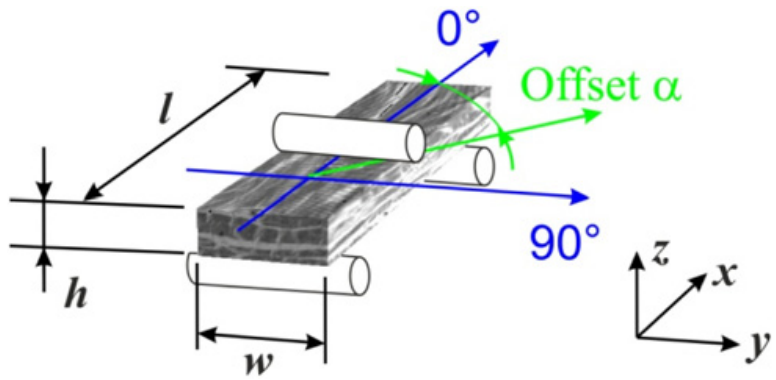

b) Definition of fibre alignment in individual coupons

Figure 6. Definition of fibre alignment for testing.

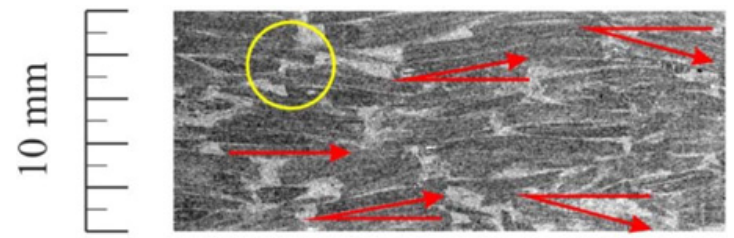

a) Fibre misalignment (red) in a coupon of unidirectionally oriented SF-C/C-SiC due to bundle overlap (yellow circle).

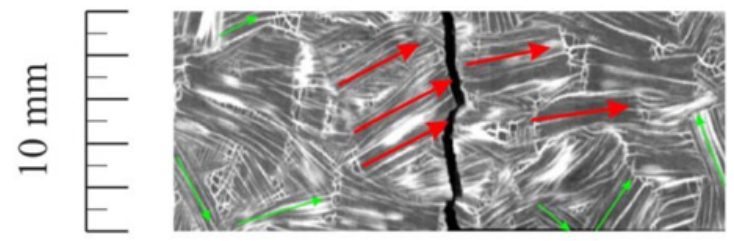

b) Local concentration of fibre bundles (red arrows) in a tested coupon of randomly distributed SF-C/C-SiC.

Figure 7. Top view of the central area of SF-C/C-SiC coupons (x-y-plane).

as seen in Fig. 7. This overlap results in individual fibre bundles having a slight offset to each other. However, this offset is small, with typically more than $75 \%$ of all fibre bundles being laid down within $\pm 10^{\circ}$ of the desired alignment (Fig. 7a). 


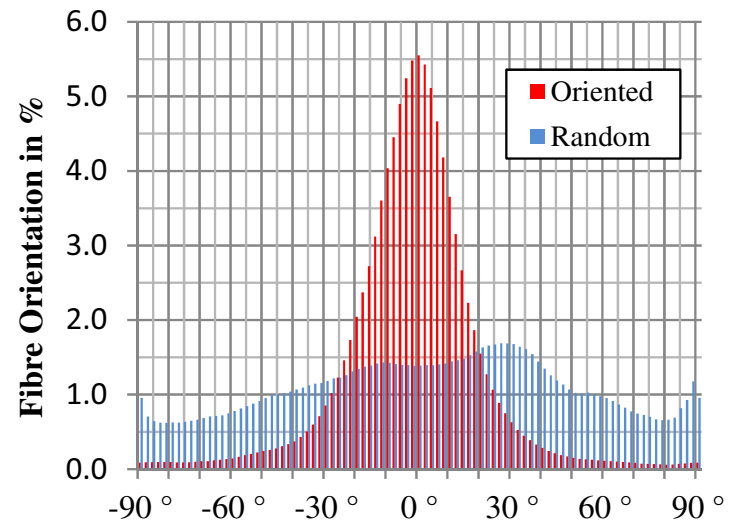

Angle in ${ }^{\circ}$

Figure 8. Angular distribution of the fibre bundles in the $x-y-p l a n e$ of an unidirectional (red) and a randomly distributed coupon (blue).

Analysis of Randomly Distributed Material

To validate the random distribution of fibre bundles, $\mu \mathrm{CT}$ data of coupons with randomly oriented fibre bundles were investigated. It can be observed that the fibre bundle distribution within the total coupon was generally randomized. Some minor alignment is observed, however these effects are only visible in individual coupons (Fig. 8).

However, local regions of the coupon can have a non-random distribution of fibre bundles. As seen in Fig 7b, small local regions of the typically random oriented coupons can be observed having a local alignment of fibre bundles.

\subsection{Mechanical testing results}

Mechanical testing was performed to determine how the fibre alignment influenced the bending strength and bending stiffness. All coupon tests were performed under identical conditions, bending stress was calculated according to DIN EN 658-3.

The stress-strain-curves of all coupons have a similar characteristic evolution (Fig. 9). Linear elastic behavior can be observed until loading reaches approximately $25 \%$ of $\mathrm{s}_{\max }$. Further loading results in a non-linear continuous progression. After reaching maximum load, a sudden decrease of stress of at least $50 \%$ is observed, signaling coupon failure.

Bending Strength Bending strength is dependent on the fibre bundle orientation. Experimental data in Table 2 show a maximum bending strength of $67 \mathrm{MPa}$ for coupons with unidirectional material oriented in $0^{\circ}$.

With an increase in fibre orientation offset from $0^{\circ}$, a reduction of bending strength occurs until a minimum of $25 \mathrm{MPa}$ is reached at $90^{\circ}$. The standard deviation for each offset remains almost constant between $4 \mathrm{MPa}$ and $6 \mathrm{MPa}$.

Coupons from randomly oriented material have an average strength of $44 \mathrm{MPa}$, with a standard deviation of $8.8 \mathrm{MPa}$.

Bending Strain

Rupture always occurrs at a strain value between $0.16 \%$ and $0.18 \%$, independent on the fibre alignment within the coupon. 


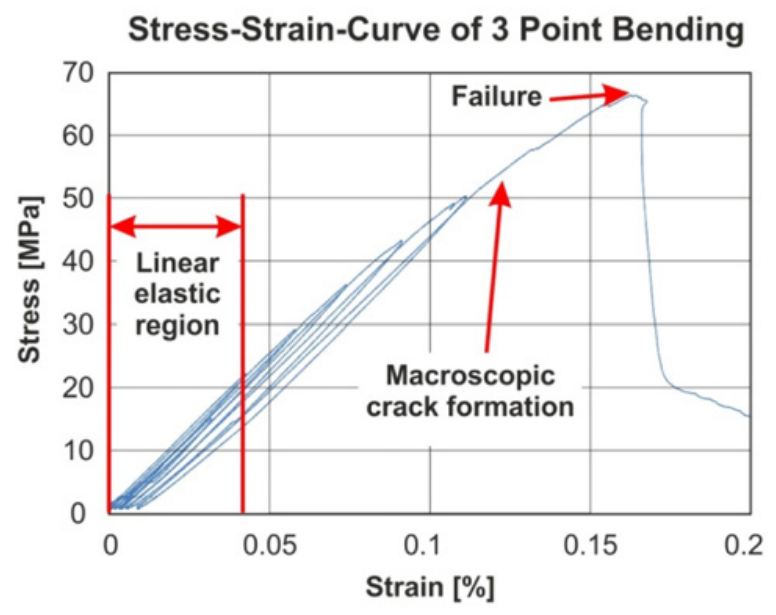

Figure 9. Stress-strain-diagram of a coupon with fibre bundles aligned in $0^{\circ}$ orientation.

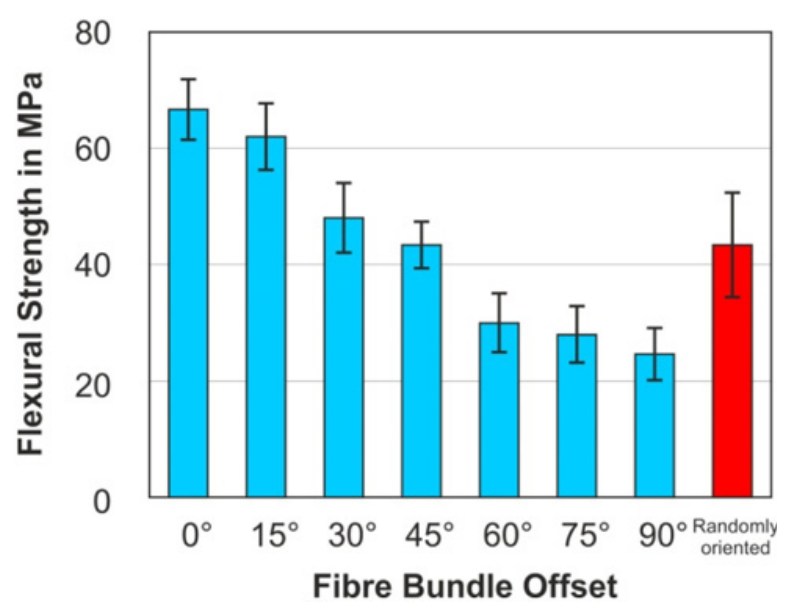

Figure 10. Three point bending strength of coupons with differently oriented and randomly distributed fibre bundles.

Bending Stiffness. The bending stiffness is dependent on the fibre bundle orientation (Table 2). A maximum bending stiffness of $45 \mathrm{GPa}$ was determined in coupons with $0^{\circ}$ unidirectional fibres. An increase in orientation offset reduced bending stiffness to a minimum value of $16 \mathrm{GPa}$ in $90^{\circ}$ oriented coupons. Coupons from random oriented material have an average stiffness of $25 \mathrm{GPa}$.

\section{Discussion}

\subsection{Influence of fibre alignment}

The experimental data show that the orientation of fibre bundles within SF-C/C-SiC material determines the mechanical material properties. As described in the polar diagrams (Figs. 12 and 13), an alignment of all fibre bundles parallel to the applied load increase the bending strength up to $50 \%$ and increase the stiffness by $80 \%$ compared to material containing random oriented fibre bundles. 


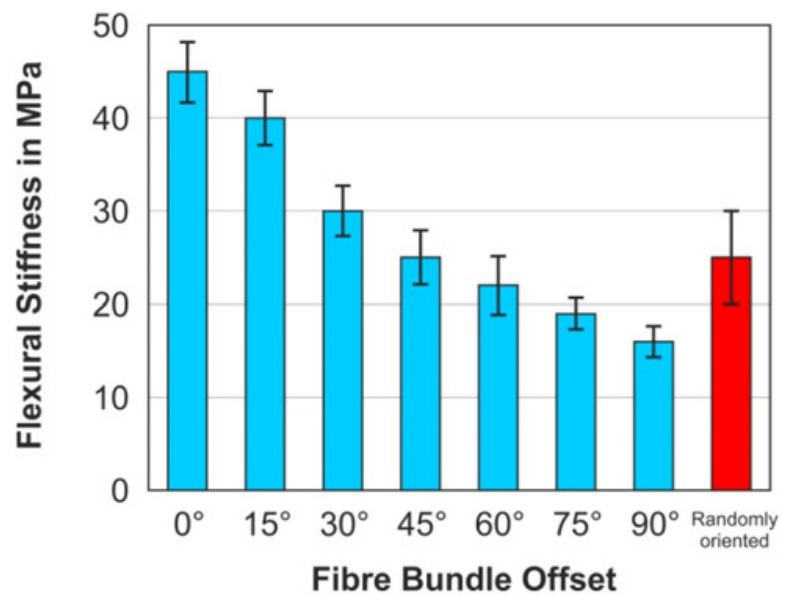

Figure 11. Three point bending stiffness of coupons with differently oriented and randomly distributed fibre bundles.

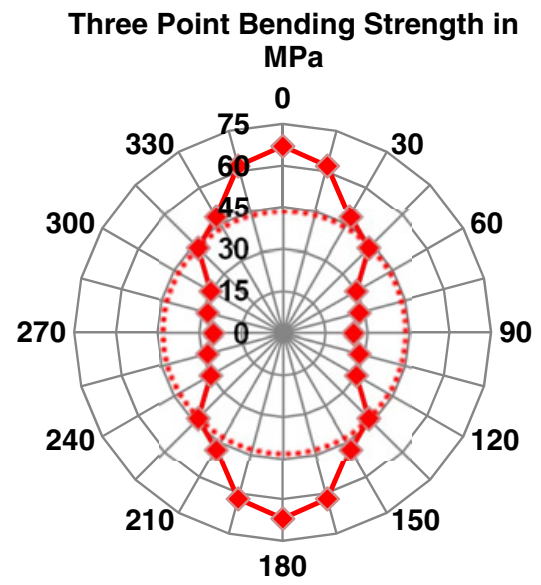

Figure 12. Polar diagram showing the distribution of bending strength based on the angle of the fibre bundle orientation. Dashed lines represent the randomly distributed material properties.

To gain an increase of the mechanical properties an exact fibre alignment is not necessary. As seen in the polar diagrams, an offset of the fibre orientation by $\pm 15^{\circ}$ result in a decrease in strength of $7 \%$ and a decrease in stiffness of $12 \%$.

\subsection{Prediction of randomly distributed material properties}

Using the known material properties of unidirectional aligned $\mathrm{C} / \mathrm{C}$-SiC, it is possible to calculate the properties of material consisting of randomly distributed fibre bundles. This can be achieved by calculating the linear mean value of the unidirectional materials properties in dependence of their angular alignment:

$$
\sigma_{\text {Random, theory }}=\frac{1}{n} \sum_{i=1}^{n} \sigma_{i}
$$




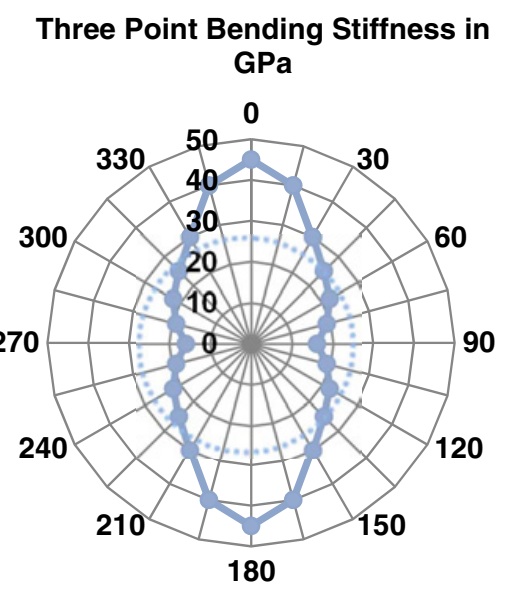

Figure 13. Polar diagram showing the distribution of bending stiffness based on the angle of the fibre bundle orientation. Dashed lines represent the randomly distributed material properties.

where $\sigma_{i}$ ist the strength of the unidirectional material with a certain offset angle. Using the determined experimental data with angular offsets of $0^{\circ} / 15^{\circ} / 30^{\circ} / 45^{\circ} / 60^{\circ} / 75^{\circ} / 90^{\circ}$, a theoretical strength for random fibre oriented material is determined to be

$$
\sigma_{\text {Random, theory }}=\frac{\sigma_{0^{\circ}}+\sigma_{15^{\circ}}+\sigma_{30^{\circ}}+\sigma_{45^{\circ}}+\sigma_{60^{\circ}}+\sigma_{75^{\circ}}+\sigma_{90^{\circ}}}{7}=44 \mathrm{MPa}
$$

This calculated value of $44 \mathrm{MPa}$ corresponds well with the experimentally determined mean strength of the randomly oriented fibres of 43.6 MPa.

\subsection{Influence of local fibre bundle alignment in randomly distributed coupons}

The analysis of the $\mu \mathrm{CT}$ data shows that the coupons extracted from the randomly distributed SF-C/C$\mathrm{SiC}$ have a local non-homogeneous distribution of fibre bundles (Fig. 7b). Considering the observed influence of the fibre alignment on bending strength, it can be assumed that these regions with local non-random alignment within the randomly oriented coupons result in the large scattering of material properties observed.

An analysis of the volumetric data in the regions where high stresses were expected (i.e. at the centre of the coupons where load is applied), shows that coupons exhibiting a high strength had a statistically higher amount of fibre bundles aligned in coupon length. Correspondingly, coupons exhibiting reduced strength have more fibre bundles aligned in coupon width (angular offset).

Effect of Coupon Size. To reduce the observed high scattering it is necessary to reduce any occurring local non-homogeneous fibre bundle distribution by increasing the testing volume of the coupon. This approach was first proposed by Weiss and Henrich [7].

A simple method to increase coupons volume would be to scale the coupon width. As shown in Fig. 14, the increase in coupons width should theoretically improve the random fibre placement, resulting in lower scattering.

Testing was performed on a series of coupons with widths of $10 \mathrm{~mm}, 20 \mathrm{~mm}$ and $30 \mathrm{~mm}$ extracted from plates with randomly oriented fibre bundles according to DIN EN 658-3. 
a) coupon with low width
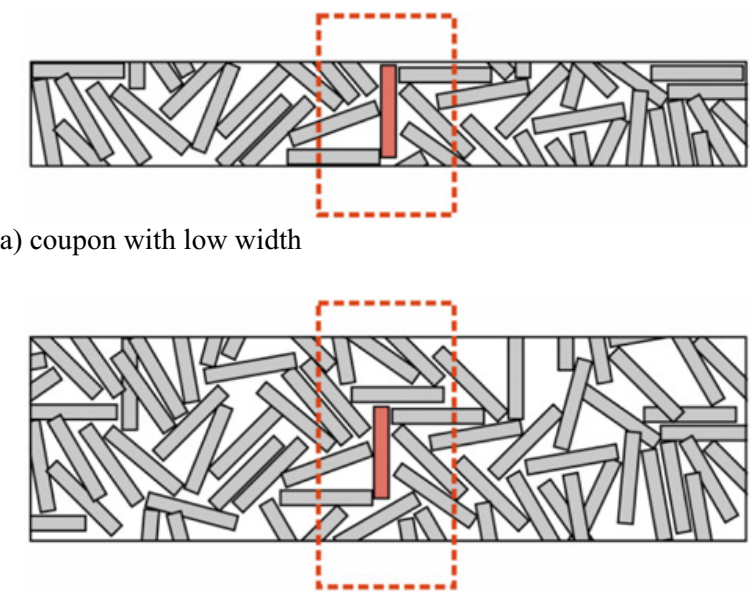

b) coupon with large width

Figure 14. Influence of coupon width on the local inhomogeneities due to fibre orientation. The non-randomly oriented fibre bundles marked red has more influence in a coupon with low width (a) than a wider coupon (b).

Table 2. Influence of coupon width on the bending strength.

\section{Point Bending Strength}

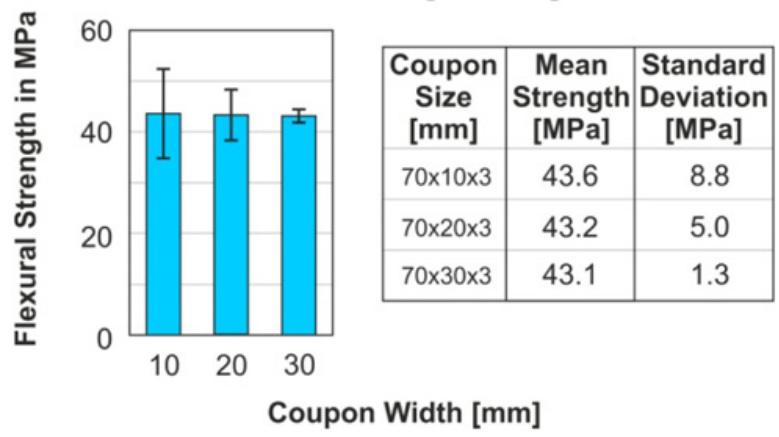

The resulting data show no significant change in the mean bending strength. However, the increase in coupon width resulted in a significant decrease of scattering. A coupon width of $30 \mathrm{~mm}$ resulted in a standard deviation of $1.3 \mathrm{MPa}$, as seen in Table 2 .

Therefore, coupon width should be adjusted to be at least 3 times as wide as the length of the short fibres used in the material tested. For representative results, it is recommended to choose a coupon width at least 5 times of the fibre length.

\section{Conclusions}

The method presented in this paper for aligning fibre bundles in short fibre reinforced $\mathrm{C} / \mathrm{C}$-SiC allows the manufacturing of material with unidirectionally oriented fibre bundles. The following results were obtained:

(1) Using volumetric $\mu \mathrm{CT}$ testing using a structure tensor approach, the alignment of fibre bundles in the material can be validated, with an average of $75 \%$ of all fibres aligned in one direction at an offset of at most $\pm 10^{\circ}$.

(2) Material made of unidirectionally aligned fibre bundles with $6 \mathrm{~mm}$ length exhibits distinct orthotropic material properties. Compared to identical material made of randomly oriented fibre bundles, the unidirectional material has a $50 \%$ increase in bending strength and an $80 \%$ increase in 


\section{MATEC Web of Conferences}

bending stiffness if loading occurs in direction of the fibre alignment. The unidirectional material does not require an exact fibre alignment, an offset of the fibre orientation of $\pm 15^{\circ}$ results only in a minor decrease in strength and stiffness.

(3) Using the experimental data obtained from the unidirectional material coupons, a simple method for predicting random distributed material properties is presented and validated.

(4) To reduce the influence of the local non-random fibre alignment, it is proposed to increase the coupon size to reduce the statistical occurrence of non-random fibre alignment and thereby improving homogenization. Testing of coupons with increased width shows a significant reduction of standard deviation. An increase in width from $10 \mathrm{~mm}$ to $30 \mathrm{~mm}$ results in a constant average bending strength remained at $44 \mathrm{MPa}$. At the same time, the standard deviation is reduced from 8.8 MPa to $1.3 \mathrm{MPa}$.

(5) For future testing, it is recommended that the coupon width used in short fibre reinforced CMC should be adjusted to consider fibre length. For optimal results, it is recommended to choose a coupon width that is at least 5 times the size of the fibre length.

\section{References}

[1] G. Ehrenstein, Faserverbundkunststoffe: Werkstoffe, Verarbeitung, Eigenschaften, Hanser Verlag, 2006, ISBN 9783446227163

[2] S. De, J. White (Ed.), Short Fibre-Polymer Composites, CRC Press, 1996, EAN 9781855732209

[3] W. Krenkel, Carbon Fibre Reinforced Silicon Carbide Composites (C/SiC, C/C-SiC), Handbook of Ceramic Composites, (Ed. N. Bansal), p. 117-148, Springer, 2005, doi: 10/1007/0-387-239863_6

[4] M. Krupka, A. Kienzle, Fiber Reinforced Ceramic Composite for Brake Discs, SAE Technical Paper 2000-01-2761, 2000, doi: 10.4271/2000-01-2761

[5] B. Heidenreich, Manufacture and Applications of C/C-SiC and C/SiC Composites, Processing and Properties of Advanced Ceramics and Composites IV: Ceramic Transactions, Vol. 234, p. 183-197, John Wiley\&Sons, 2012

[6] M. Henrich, D. Regener, R. Weiß, On the influence of cross section in tensile tests of siliconized short carbon fibre reinforced carbon (C/C-SiC). Mat.-wiss. u. Werkstofftech., 35: 45-54, (2004), doi: 10.1002/mawe.200300659

[7] R. Weiss, M. Henrich, Short-Fiber Reinforced CMCS: Potentials and Problems, in Mechanical Properties and Performance of Engineering Ceramics and Composites: Ceramic Engineering and Science Proceedings, Volume 26, Number 2 (Ed. E. Lara-Curzio), John Wiley \& Sons, Inc., NJ, USA, 2005 doi: 10.1002/9780470291221.ch42

[8] D. Heim, S. Zaremba, C. Klotz, K. Drechsler, Parameter study of short carbon fiber reinforced carbon, Proc. 18th intl. conf. on. Comp. mat., 2009, Edinburgh, Scotland

[9] W. Krenkel, J. Hausherr, Carbon Fiber Reinforced Ceramic Matrix Composites for Friction Applications, Proc. 30th Intl. Conf. on Adv. Cer. and Comp., 2006, Cocoa Beach, USA

[10] DIN EN 1389:2003, Advanced technical ceramics - Ceramic composites - Physical properties Determination of density and apparent porosity

[11] DIN EN 658-3:2002, Advanced Technical Ceramics - Mechanical Properties of Ceramic Composites at room temperature - Part 3: Determination of Flexural Strength

[12] M. Krause, J. Hausherr and W. Krenkel, Computing the fibre orientation from radon data using local radon transform, Inverse Problems and Imaging Vol. 5, No. 4, 879-891, 2011, doi: 10.3934/ipi.2011.5.879

[13] M. Krause, J. Hausherr, B. Burgeth, C. Herrmann and W. Krenkel, Determination of the fibre orientation in composites using the structure tensor and local X-ray transform, J Mater Sci 45: 888-896, 2010. doi: 10.1007/s10853-009-4016-4 